\title{
Microstructures of the Osseous Spiral Laminae in the Bat Cochlea: A Scanning Electron Microscopic Study
}

\author{
Babür KüÇÜK $\mathbf{K}^{1,2}$ and Kazuhiro $\mathbf{A B E}^{1}$ \\ Department of Anatomy ${ }^{1}$, Hokkaido University School of Medicine, Sapporo, Hokkaido; and Department of Otolaryngology ${ }^{2}$, \\ Tokai University School of Medicine, Isehara, Kanagawa, Japan
}

Received May 22, 1992

Summary. The architecture and surface structures of the primary and secondary osseous spiral laminae in the cochlea of the bat, an animal able to hear high frequency sounds, were examined by scanning electron microscopy to understand the micromechanical adaptations of the bony supportive elements in the inner ear to the specific hearing function. The bat used was Myotis frater kaguyae.

The myotis bat cochlea was seen to consist of a hook and a spiral portion with one and three-quarter turns and was characterized by: 1) a distinct ridge-like projection running spirally along the middle line on the vestibular leaf of the primary osseous spiral lamina; 2) a wide secondary osseous spiral lamina; and 3) a narrow spiral fissure between the primary and secondary osseous spiral laminae. The ridge on the primary osseous spiral lamina was $150 \mu \mathrm{m}$ high in the hook and basal turn, then lowered toward apex, and flattened before the apical end. The surface structures appeared to provide a firm anchorage of the auditory teeth. The secondary osseous spiral lamina, which anchors the fibers of the basilar membrane, was sharply projected and measured $150 \mu \mathrm{m}$ in width in the hook, and then narrowed gradually toward apex to disappear in the helicotrema. The spiral fissure for the basilar membrane was about $40 \mu \mathrm{m}$ in width in the hook and about $120 \mu \mathrm{m}$ in the apical turn.

The findings suggest the presence of a narrow and rigid basilar membrane with a high amount of fibers and a strong bony support to the auditory teeth for scaffolding the tectorial membrane during intense vibration in response to high frequency sounds. The above-mentioned specialized structures of the primary and secondary osseous spiral laminae in the bat cochlea appear to adapt to the micromechanics of high frequency hearing functions.

In the mammalian cochlear duct, the basilar membrane underlying the organ of Corti is stretched between the free margins of the primary and secon- dary osseous spiral laminae. High frequency sounds vibrate the membrane in the basal regions of the cochlear duct, while relatively lower frequency sounds vibrate the membrane in the apical regions (BEKESY, 1960). Using the mouse cochlea, we have suggested that the regional vibration pattern of the basilar membrane is closely related to the base-toapex variations in the morphology of the osseous spiral laminae (KÜçÜK and ABE, 1989). It is known that the bat cochlea is sensitive to sounds in the very high frequency range. In fact, the frequencies of the sounds that stimulate the basilar membrane in the bat cochlea are higher than those that stimulate the basal regions of the basilar membrane in the mouse cochlea (BRUNS and SCHMIESZEK, 1980; NEUWILLER, 1984). To increase our understanding about the relationship between high frequency hearing functions and the bony supportive elements in the cochlea, the bat cochlea was deemed the optimum model. In this study, we examined the surface structures of the primary and secondary osseous spiral laminae in the bat cochlea by scanning electron microscopy (SEM).

\section{MATERIALS AND METHODS}

This study used eight temporal bones obtained from four bats, Myotis frater kaguyae, which had been preserved in $10 \%$ formaldehyde solution for 6 years. After immersing the temporal bones in $6 \% \mathrm{NaOCl}$ to macerate the soft tissues, the cochlear canals were opened with needles from various directions undèr a stereo-microscope. The specimens were then washed, dehydrated with acetone, dried in air, mounted onto aluminum stubs, coated with platinum-paladium in an ion coater and examined by SEM.

For measurements of several cochlear components, two cochleae were used. 


\section{RESULTS AND DISCUSSION}

Previously in the mouse cochlea, we indicated that the primary and secondary osseous spiral laminae, which support the basilar membrane, differ in structural characteristics between the high frequency and the low frequency regions in relation to the regional mechanical functions of the cochlea (KÜÇüK and ABE, 1989). As shown in the present study, the osseous spiral laminae of the bat cochlea appear to have special features that allow adaptation to the cochlear mechanics involved in the perception of the very high frequency sounds.

In the myotis bat, the primary osseous spiral lamina consisted of a basal hook and a spiral portion with one and three-quarter turns; the last quarter turn formed the sickle-shaped hamulus (Fig. 1a, b). The lamina was about $200 \mu \mathrm{m}$ wide in the hook and $150 \mu \mathrm{m}$ wide in the apical turn. The vestibular leaf of the primary osseous spiral lamina projected a sharp ridge into the scala vestibuli along the middle line between the modiolus and the free edge of the lamina (Figs. 1c, 2a-d). The ridge was continuous from the basal end of the hook to the hamulus (Fig. 1). The ridge stood obliquely on the osseous spiral lamina (Figs. 1c, 2a-d). The height of the ridge from the plane of the free margin of the primary osseous spiral lamina was about $150 \mu \mathrm{m}$ in the hook and basal turn, the height then slightly decreasing toward the hamulus to become flattened just before the apical end. Such a prominent vestibular ridge has also been observed in the dolphin, a mammal which also hears sounds at ultra-high frequencies (FLEISCHER, 1976). In contrast, the mouse cochlea shows a vestibular ridge only in the basal turn, and the ridge is low (KüçüK and ABE, 1989). The human cochlea, which is sensitive to relatively low frequency sounds, has no such ridge (KÜÇÜK and ABE, 1991; NEUwILlER, 1984).

The bone surfaces on the cochlear canal side and modiolar side of the vestibular ridge in the bat showed different appearances. The surface on the modiolar side revealed a meshwork of irregular bony trabeculae and holes for vasculatures (Fig. 2a, c, d). This surface appears similar to the inner half of the primary osseous spiral lamina in the mouse but was richer in trabeculae and holes, suggesting denser vasculatures to the overlying spiral limbus. The surface on the cochlear canal side had the appearance of a honeycomb-like structure composed of many cristae and lacunae which were about $8 \mu \mathrm{m}$ wide (Fig. 2b, d). This area appears similar to the bone surface underlying the vestibular lip of the spiral limbus in the mouse and is believed to form an insertion site for the connective tissue fibers of the auditory teeth, thus supporting the tectorial membrane overlying the teeth (IURATO, 1962; KÜÇÜK and ABE, 1989, 1990).

The primary osseous lamina was accompanied by $\mathbf{a}$

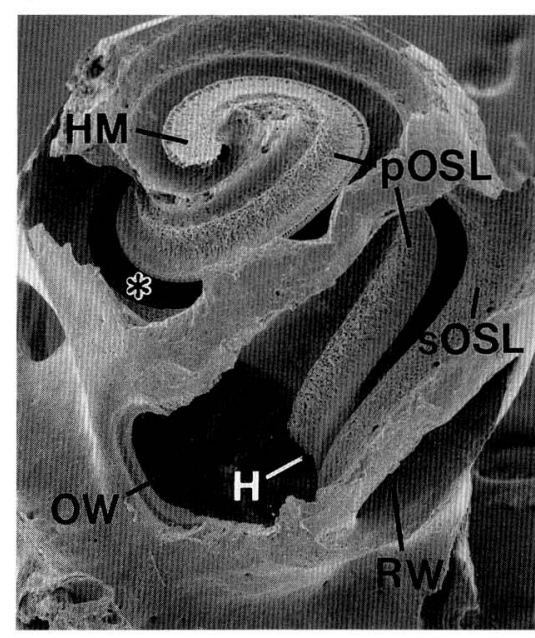

b

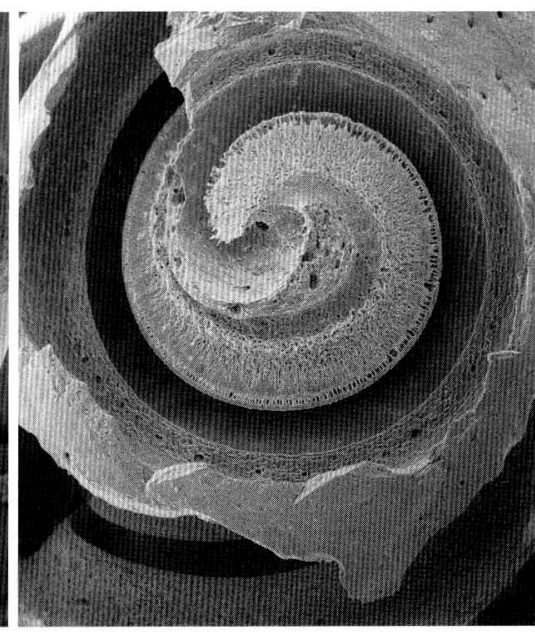

c

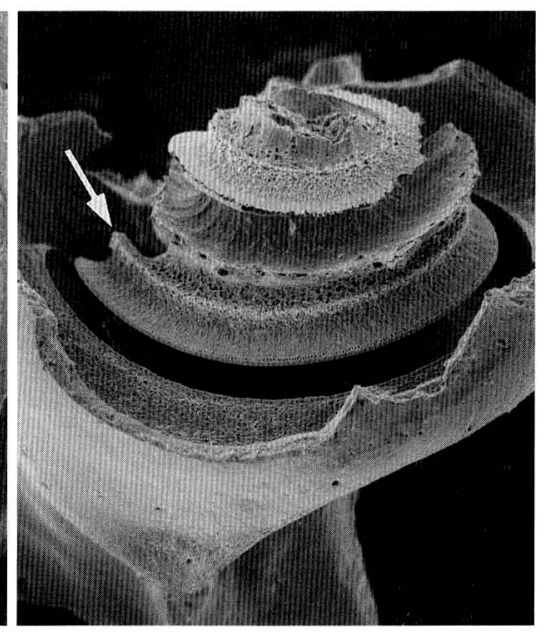

Fig. 1. Bony labyrinth of the right cochlea in the myotis bat. a. Top-oblique view: $p O S L$ primary osseous spiral lamina, sOSL secondary osseous spiral lamina, $H$ hook, $H M$ hamulus, $R W$ round window, $O W$ oval window. The upper and lower spaces divided by two osseous spiral laminae are the scala vestibuli and scala tympani. $\times 40$. b. Top view. The helicotrema is located at the top of the hamulus. $\times 50$. c. Lateral view. Note the sharp spiral ridge (arrow) on the primary osseous lamina. $\times 40$ 

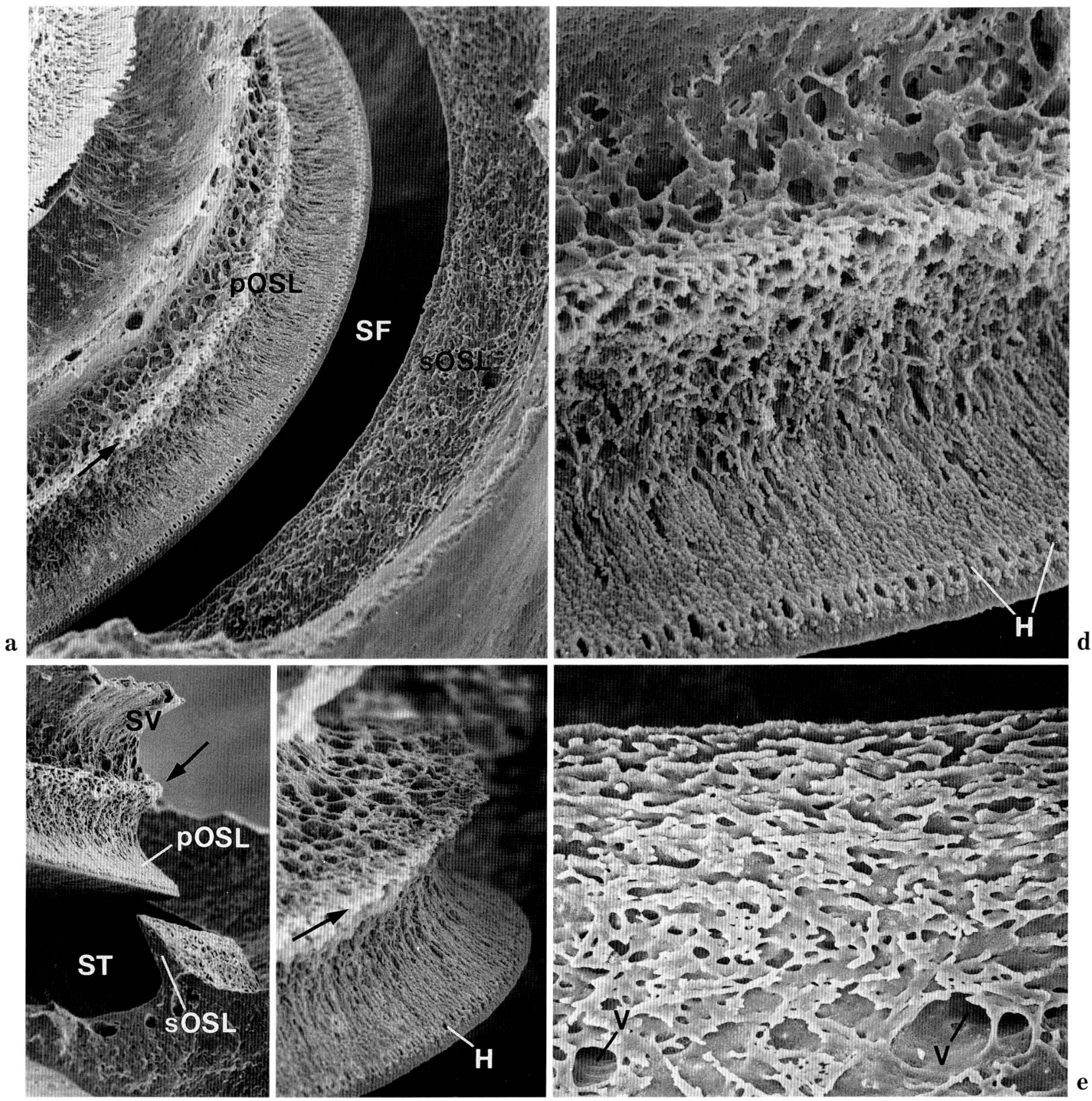

b

c

Fig. 2. Closer views of the bony labyrinth in the myotis bat: pOSL primary osseous spiral lamina, sOSL secondary osseous spiral lamina, $S F$ spiral fissure, $S V$ scala vestibuli, $S T$ scala tympani, a. Top-oblique view of the osseous spiral laminae. The vestibular ridge (arrow) on the $p O S L$ is well demonstrated. $\times 120$. b. Bottom-oblique view of $p O S L$ and $s O S L$. The orientations of the $p O S L, s O S L$ and $S F$ are well demonstrated. An arrow indicates the vestibular ridge. $\times 100$. c. Top-oblique magnified view of $p O S L$. $H$ habenular openings. The vestibular ridge (arrow) obliquely projects to the scala vestibuli. $\times 200$. d. Oblique-frontal view of $p O S L$. The modiolar surface (upper) and the surface facing the cochlear canal (lower) differ in appearance. Habenular openings line along the edge of $p O S L . \times 400$. e. Top view of $s O S L$. V vascular openings. The area near the free margin consists of bony lamellae oriented parallel to the margin. $\times 400$ 
the secondary osseous lamina from the basal end of the hook to the apical end of the hamulus (Figs. 1, 2a, b). The secondary osseous lamina projected sharply from the lateral wall in the hook and the basal turn. This lamina measured about $150 \mu \mathrm{m}$ in width at the basal turn, then gradually narrowed toward the apex to disappear in the helicotrema. In the bat cochlea, the width of the secondary osseous spiral lamina was almost equal to the width of the primary osseous spiral lamina, being remarkably wide. In the mouse, the width of the secondary lamina is about $100 \mu \mathrm{m}$, one third that of the primary lamina (KÜçÜK and ABE, 1989). Lastly, in the human cochlea the secondary lamina is absent except for a slight projection in the very basal regions (KÜÇÜK and ABE: unpublished data). Thus, the secondary osseous lamina in the bat appears to be wider than that in the mouse and human. The surface of the secondary osseous lamina, however, appeared similar to that of the mouse (KÜÇÜK and ABE, 1989); it was composed of thin lamellae-like scales elevated obliquely to the scala vestibuli, separated by narrow indentations, and arranged parallel to the edge of the lamina (Fig. 2e). Such surface elements of the lamina are considered to anchor the basilar membrane fibers (IURATO, 1962; KÜÇÜK and ABE, 1989), thus stabilizing the membrane during its vibrations in response to sound waves.

The frequencies of the sound waves that vibrate the basilar membrane are in the range of 20 to over $150 \mathrm{kHz}$ in the bat and dolphin cochlea, 1 to $80 \mathrm{kHz}$ in the mouse cochlea, and 0.1 to $20 \mathrm{kHz}$ in man (Neuwiller, 1984; Evans, 1973; EHret, 1975). It is generally known that the vibration pattern of the basilar membrane in the cochlea is determined by the base-to-apex gradient in the stiffness of the membrane: this gradient is due to the base-to-apex variations in the width and thickness of this membrane (BEKESY, 1960). In the mouse, the width of the basilar membrane was about $130 \mu \mathrm{m}$ and almost constant along the cochlear duct, while the thickness decreased from base to apex (KÜÇÜK and ABE, 1989). In the myotis bat, the width of the spiral fissure for the basilar membrane between the edges of the primary and secondary osseous laminae was about $40 \mu \mathrm{m}$ in the hook and basal turn and about $120 \mu \mathrm{m}$ in the apical turn. This reflects the fact that the basilar membrane, closing the spiral fissure, is very narrow in the base but wider in the apex. The basilar membrane in the myotis bat appears to be relatively thicker because the secondary osseous lamina which anchor the fibers of the basilar membrane is wider than that in the mouse and human; this indicates the presence of a higher amount of fibers in the basilar membrane. It is understandable that the relatively narrow and thick basilar membrane found in the bat cochlea probably has a much greater rigidity that allows the membrane to vibrate with high frequency sounds.

The basilar membrane vibrates together with the tectorial membrane (BEKESY, 1960; STRELIOFF, 1985). The tectorial membrane is fixed to the auditory teeth on its inner margin and remains free on the outer margin to overlie and touch the organ of Corti on the basilar membrane. The extremely rapid vibrations of the tectorial membrane during high frequency sounds probably cause great mechanical stress to the auditory teeth supporting the membrane. As mentioned above, the teeth are scaffolded by the well-developed vestibular bony ridge on the primary osseous lamina. The ridge on the primary osseous spiral lamina is thus considered to be involved in the vibration micromechanics of the tectorial membrane for the perception of very high frequency sounds.

The micromechanical functions of the very high frequency regions in the bat cochlea are thus considered to be partly determined by the surface structures of the primary and secondary osseous spiral laminae. Related with the perception of very high frequency sounds, the cochlea in the mustache bat and the greater horseshoe bat has been demonstrated in light and electron microscopic studies to possess a denser population of nerve fibers of the organ of Corti along the very high frequency regions (BRUNS and SCHMIESZEK, 1980; ZoOK and LEAKE, 1989). The nerve fibers from the organ of Corti are transmitted through the habenular openings aligned along the free margin of the primary lamina. In the myotis bat cochlea, the openings were arranged in constant period of $8 \mu \mathrm{m}$ from the basal end of the hook to the hamulus and measured about $3 \mu \mathrm{m}$ in diameter in the hook and $6 \mu \mathrm{m}$ at the beginning of the apical turn (Figs. 1b, 2a, c, d). The base-to-apex increase in size of the openings may imply a base-to-apex increase in the population density of the nerve fibers of the organ of Corti. The distribution of the neuronal elements in the myotis bat cochlea and their significance for the very high frequency hearing functions need, however, to be elucidated with further histological studies.

Acknowledgements. We are indebted to Prof. K. ONO and Associate Prof. Y. SATO, in the Department of Anatomy Asahikawa Medical College, for kindly supplying the bats used in this study. We are also thankful to Prof. M. IGARASHI, from the Department of Otolaryngology, Tokai University School of Medicine, for reviewing the manuscript. Special thanks are due to Josef ScHMID III, a student from Bowman Gray Medical School, North Carolina, USA, for proofreading of the manuscript. 


\section{REFERENCES}

BÊKÉsy, G. V.: Experiments in hearing. McGraw Hill, New York, 1960.

Bruns, V. and E. Schmieszek: Cochlear innervation in the greater horseshoe bat: Demonstration of an acoustic fovea. Hearing Res. 3: 27-43 (1980).

EHRET, G.: Masked auditory thresholds, critical ratios, and scales of the basilar membrane of the housemouse (Mus musculus). J. Comp. Physiol. 103: 329-341 (1975).

Evans, W. E.: Echolocation by marine delphinids and one species of fresh-water dolphin. J. Acoust. Soc. Amer. 54: 191-199 (1973).

Fleischer, G.: On bony microstructures in the dolphin cochlea, related to hearing. Neu. Jahrb. Geol. Palaontol. Abhandl. 151: 166-191 (1976).

IURATO, S.: Submicroscopic structure of the membranous labyrinth, III. The supporting structure of Corti's organ (basilar membrane, limbus spiralis and spiral ligament). Z. Zellforsch. 56: 40-96 (1962).

KüçüK, B. and K. ABE: Microanatomy of the mouse osseous cochlea: A scanning electron microscopic study. Arch. Histol. Cytol. 52: 173-182 (1989).

-: Scanning electron microscopy of the auditory teeth along the mouse cochlea duct. Arch. Histol. Cytol. 53: 439-448 (1990).

Microstructures of the bony modiolus in the human cochlea: A scanning electron microscopic study. J. Electron Microsc. 40: 193-197 (1991).
Neuwiller, G.: Auditory basis of echolocation in bats. In: (ed. by) L. Bolis, R. D. Keynes, S. H. P. MADDRELL: Comparative physiology of sensory systems. Cambridge University Press, Cambridge, 1984 (p.115-141).

Strelioff, D., Å. Flock and K. E. Minser: Role of inner and outer hair cells in mechanical frequency selectivity of the cochlea. Hearing Res. 18: 169-175 (1985).

Zook, J. M. and P. A. LEAKE: Connections and frequency representation in the auditory brainstem of the mustache bat, Pteronotus parnelli. J. Comp. Neurol. 290: 243-261 (1989).
Prof. Kazuhiro ABE

Department of Anatomy

Hokkaido University School of Medicine Kita-15, Nishi-7, Kita-ku 060 Sapporo, Japan

阿 部 和 厚 060 札幌市北区北 15 条西 7 丁目 北海道大学医学部 解剖学第三講座 